\title{
COMITÊ OLÍMPICO BRASILEIRO E O FINANCIAMENTO DAS CONFEDERAÇÕES BRASILEIRAS
}

\author{
MS. BÁRBARA SCHAUSTECK DE ALMEIDA \\ Aluna do Programa de Doutorado em Educação Física pela \\ Universidade Federal do Paraná (Paraná - Brasil) \\ e-mail: barbara.edf@ufpr.br
}

\section{DR. WANDERLEY MARCHI JÚNIOR}

Doutor em Educação Física pela Unicamp e Professor do Departamento de Educação

Física e de Ciências Sociais da Universidade Federal do Paraná (Paraná - Brasil)

e-mail:marchijr@ufpr.br

\begin{abstract}
RESUMO
O esporte olímpico no Brasil tem como importantes instituições de administração o Comitê Olímpico Brasileiro (COB) e as confederações brasileiras de modalidades olímpicas. Mas de que forma elas se relacionam financeiramente e como isso interfere na dinâmica do campo esportivo brasileiro? Com a coleta de dados em relatórios oficiais e com o subsídio teórico do sociólogo Pierre Bourdieu, percebemos que os repasses do COB às confederações brasileiras reforçam posições dominantes e dominadas no campo esportivo. A justificativa para as atuais formas de repasses são paradoxais à proposta de desenvolvimento do esporte no país. Nesse sentido, alguns conceitos de Bourdieu auxiliam a desvelar alguns fundamentos ocultos de dominação presentes no campo esportivo do país sede dos Jogos Olímpicos de 2016.
\end{abstract}

PALAVRAS-CHAVE: Brasil; esporte; organização e administração; financiamento. 


\section{INTRODUÇÃO}

A compreensão do Movimento Olímpico, na forma pela qual ocorre em perspectivas internacionais, nos auxilia na compreensão da dinâmica do campo esportivo brasileiro com relação ao esporte olímpico.

Para o Comitê Olímpico Internacional (COI), o Movimento Olímpico é composto por diversos agentes que, responsáveis pela manutenção do espírito olímpico, formam a "família olímpica". Seus componentes são: a população mundial, a população mundial jovem, espectadores, os melhores atletas do mundo, a mídia credenciada para os Jogos, os transmissores midiáticos, os patrocinadores do COI, os Comitês Olímpicos Nacionais, as Federações Internacionais e os Comitês Organizadores dos Jogos Olímpicos, e, na ponta da pirâmide, encontramos o COI (INTERNATIONAL OLYMPIC COMMITTEE, 2007).

Sendo o COI a entidade máxima representativa do Movimento Olímpico, podemos refletir sobre quais são as entidades que estão diretamente relacionadas ao esporte olímpico no contexto brasileiro, que também fazem parte da "família olímpica". Assim, apropriando a pirâmide do COI ao contexto nacional, teríamos os seguintes agentes: população brasileira, população brasileira jovem, espectadores brasileiros, os melhores atletas do país, mídia brasileira credenciada para os Jogos, transmissores midiáticos para o Brasil, patrocinadores do Comitê Olímpico Brasileiro (COB), confederações brasileiras e o próprio COB.

Mostrada essa macroestrutura organizacional do esporte, onde algumas das inter-relações entre diferentes instituições do Movimento Olímpico brasileiro foram evidenciadas, focaremos a relação $\mathrm{COB}$ e confederações brasileiras.

Atualmente, o COB se relaciona diretamente com 29 confederações brasileiras de modalidades olímpicas, sendo duas relacionadas aos Jogos Olímpicos de Inverno. Além disso, há o vínculo e reconhecimento com outras 23 confederações de modalidades não olímpicas (COMITÊ OLÍMPICO BRASILEIRO, 20I0). Mas em consideração à quantidade de modalidades que são filiadas às confederações olímpicas, o número é de 43 (COMITÊ OLÍMPICO BRASILEIRO, 2007).

A respeito das 43 modalidades olímpicas, administradas pelas 29 confederações brasileiras, nos concentramos nessa pesquisa em compreender o relacionamento entre essas confederações e o COB: de que forma as confederações e o $\mathrm{COB}$ se relacionam financeiramente e como essa relação interfere na dinâmica do campo do esporte olímpico brasileiro?

Abordamos especificamente o repasse de verbas provenientes da Lei $n^{\circ}$ 10.264/200 I, conhecida como Lei Agnelo-Piva, do COB para as confederações. No decorrer da pesquisa, percebemos que esses repasses representam uma quantidade 
muito significativa de recursos na realidade das confederações no período observado e evidenciam as disputas de poder dentro do campo esportivo brasileiro para o esporte olímpico.

Assim, se estabeleceram como objetivos: (I) Identificar de que forma há o relacionamento financeiro entre as confederações brasileiras de modalidades olímpicas e o COB, com base no repasse de recursos provenientes da Lei $n^{\circ} 10.264 / 200$ I durante os anos de 2006 a 2009; (2) Delinear quais são as posições e disposições dos dominantes e dominados no campo do esporte olímpico brasileiro a partir da dinâmica de poder que se estabelecem quando observadas as relações entre o $C O B$ e as confederações olímpicas; (3) Discutir os critérios de repasse dos recursos provenientes da Lei n ${ }^{\circ}$ 10.264/200 I durante os anos de 2006 a 2009 pelo COB para as confederações brasileiras para o desenvolvimento das modalidades olímpicas no Brasil.

A justificativa para esse estudo tornou-se ainda mais evidente após o dia 02 de outubro de 2009, quando o Rio de Janeiro foi anunciado como cidade-sede dos Jogos Olímpicos de 2016. Com esse fato estabelecido, acreditamos que a necessidade de desenvolvimento de estudos que possam tornar-se base para discussão e futura intervenção seja uma tendência expressiva e significativa entre os pesquisadores. Apesar de renomados pesquisadores terem se dedicado ao estudo do Olimpismo nos últimos anos', não pudemos encontrar estudos específicos sobre a administração do esporte olímpico, área de relevante potencial de crescimento nos próximos anos em nosso país.

Ainda que a proposta dessa pesquisa seja examinar o financiamento de uma entidade administradora, ele se caracteriza como um estudo qualitativo que visa a "explicação do funcionamento das estruturas sociais" (RICHARDSON, 2008, p. 82). Os dados foram coletados em fontes oficiais, principalmente da internet, meio pelo qual esses dados são disponibilizados e de livre acesso.

Os principais dados foram obtidos a partir dos relatórios através dos quais o $\mathrm{COB}$ presta contas do investimento dos recursos provenientes da Lei $n^{\circ} 10.264 / 2001$, a Lei Agnelo-Piva. Utilizamos os relatórios referentes aos anos de 2006, 2007 e 2008, porém estendemos a análise também para o ano de 2005, já que o relatório de 2006 traz alguns dos dados do ano anterior. Até o início de abril de 2010, as informações sobre o ano de 2009 ainda não tinham sido disponibilizadas. Os relatórios são disponibilizados para download no

I. Destaca-se o Centro de Estudos Olímpicos da Universidade Gama Filho, coordenado pelo Prof. Lamartine DaCosta e outros professores, que possui publicações desde 1999 e inclui parcerias com universidades de países como China, Espanha, Inglaterra e Alemanha. Para mais informaç̧ões, inclusive de publicações, consultar em: <http://www.ugf.br/editora/ceo/index.htmll>. 
endereço eletrônico do COB anualmente, porém os relatórios dos anos anteriores são retirados. Em razão do nosso envolvimento com estudos relacionados a essa instituição ter sido iniciado no começo de 2007, temos os arquivos salvos desde 2006, o que permitiu essa análise.

A análise das informações foi feita com uma abordagem sociológica, com base na teoria do autor Pierre Bourdieu. Tais interpretações foram apresentadas de forma concomitante à exposição dos dados empíricos, mas enfatizadas na seção de discussão.

Esse artigo está dividido em três partes, além da introdução já apresentada. Primeiro, apresentamos algumas características das entidades que administram o esporte olímpico no país, evidenciando o relacionamento que elas possuem quanto ao financiamento. Em seguida, realizamos uma discussão sobre o campo do esporte olímpico no país, delineando algumas de suas relações e posições. Por último, nas considerações finais, retomamos as possíveis respostas para problema de pesquisa, reforçando algumas exposições do decorrer do trabalho e dando alguns indicativos de consequências das situações mostradas.

\section{AS ENTIDADES ADMINISTRADORAS DO ESPORTE OLÍMPICO: O COMITÊ OLÍMPICO BRASILEIRO E AS CONFEDERAÇÕES BRASILEIRAS}

O COB é a entidade que representa o movimento olímpico no Brasil conforme reconhecimento do $\mathrm{COI}$ e da legislação brasileira.

A criação do $\mathrm{COB}$ está diretamente ligada à criação do $\mathrm{COI}$, em I894, pelo Barão Pierre de Coubertin. Para viabilizar a retomada dos Jogos Olímpicos em escala mundial - objetivo inicial do $\mathrm{COI}$-, alguns dos seus membros fundadores, além de representantes de seus países, também eram embaixadores do COI pelo mundo, inaugurando, assim, os primeiros Comitês Olímpicos Nacionais (ABREU et al., 2006).

Institucionalmente, o COB, já com essa designação, só foi oficializado em 20 de maio de 1935 pelas leis brasileiras e sob os princípios da Carta Olímpica. Porém, foi somente a partir do Decreto-Lei 3. 199/194I que os esportes olímpicos ficaram sobre o amparo somente do COI e do COB no território brasileiro (ABREU et al., 2006). Independente disso, o COI reconhece a data de criação do COB como 8 de junho de 1914 (COMITÊ OLÍMPICO BRASILEIRO, 2004a).

Para o COI, os Comitês Olímpicos Nacionais devem ter como missão: a promoção dos princípios do Olimpismo em nível nacional, suporte ao desenvolvimento de atletas, treinamento de administradores esportivos pela organização de programas educativos, seleção e envio de equipes aos Jogos Olímpicos, além de 
pré-selecionar as cidades de seu território para candidatura à sede de Jogos Olímpicos (INTERNATIONAL OLYMPIC COMMITTEE, 2007).

Dentre as competências indicadas no estatuto do COB, baseadas na Carta Olímpica para promoção do Movimento Olímpico, destacam-se: desenvolvimento, propagação, organização, direção e coordenação do desporto no país; organizar a representação do Brasil em Jogos; ser o representante do Brasil internacionalmente, assim como representar com exclusividade o Movimento Olímpico frente aos Poderes Públicos; designar e eleger a cidade candidata à sede de competições, adotando medidas para organização e realização dos Jogos quando a cidade for aceita; coibir ações discriminatórias, violentas e o uso de doping; fomentar demais atividades relacionadas ao Movimento Olímpico (COMITÊ OLÍMPICO BRASILEIRO, 2004b).

Para cumprir com essas competências, o COB possui receita de patrocinadores, parceiros e fornecedores, mas principalmente recebe financiamento público de diversas formas². A ligação financeira que se dá entre COB e as confederações brasileiras é decorrente da Lei n 10.264/2001, conhecida como Lei Agnelo-Piva.

Essa proposição acrescentou incisos e parágrafos à Lei n 9.615 de 1998, a Lei Pelé, em seu artigo 56, que trata do financiamento do desporto. As principais alterações provocadas pela Lei Agnelo-Piva consistem em regulamentar o repasse de $2 \%$ da arrecadação dos prognósticos, loterias federais e similares, deduzidos os valores dos prêmios, ao COB e ao Comitê Paraolímpico Brasileiro (CPB). Desses 2\%, 85\% do montante são repassados ao COB e I 5\% ao CPB (BRASIL, 200I), ou seja, o COB recebe I,7\% da arrecadação bruta e o CPB 0,3\%.

Além disso, a lei regulamenta que 10\% devem ser aplicados em ações de esporte escolar e 5\% em esporte universitário, e que o Tribunal de Contas da União (TCU) deve fiscalizar o repasse e aplicação das verbas (BRASIL, 200I).

$\bigcirc$ investimento desses recursos se dá em seis ações, sob as quais o $C O B$ estabeleceu que: (I) "programas e projetos de fomento" são candidaturas para eventos internacionais, aquisição de equipamentos e materiais, administração de unidades como centros, museu e academia olímpicos; (2) "manutenção da entidade" é a manutenção administrativa do COB e das confederações brasileiras; (3) "formação de recursos humanos" é a realização e participação em eventos técnicos e a formação de mão-de-obra especializada no esporte; (4) "preparação técnica"

2. O COB recebeu $R \$ 389,7$ milhões de 2005 a 2008 a partir dessas fontes de recursos. Desse montante, os repasses pela Lei Agnelo-Piva somam R \$ I 4,9 milhões. Outras fontes de financiamento, direta ou indiretamente público, foram: $\mathrm{R} \$ 26$, I milhões pela captação de recursos através da Lei de Incentivo ao Esporte (Lei n I l.438/2006); R\$ 45, I milhões através do repasse governamental a instituições sem fins lucrativos; e $\mathrm{R} \$$ 3,6 milhões em patrocínio e parcerias com as empresas de capital público Petrobras, Caixa Econômica Federal e Correios (ALMEIDA, 20 I0). 
é o treinamento de equipes, infraestrutura, contratação e remuneração de comissões técnicas; (5) "manutenção de atletas" é o pagamento de despesas diversas de treinamento e competições nacionais e internacionais; e (6) "organização e participação em eventos esportivos" é a realização e participação em treinamentos e competições nacionais e internacionais (COMITÊ OLÍMPICO BRASILEIRO, 2006; 2007). Nessas normativas, não houve a indicação de qual o percentual mínimo do total de recursos recebidos que deveria ser investido em cada ação.

O repasse de recursos do $\mathrm{COB}$ se dá somente para as confederações brasileiras de esportes olímpicos, de acordo com critérios próprios que, somente em 2009 foram explicitados, como discutiremos a seguir. De 2005 a 2008, pudemos notar que o repasse de recursos da Lei Agnelo-Piva para as confederações pode ser classificado em três blocos, por percentual de recebimento de recursos.

No primeiro bloco, encontram-se onze confederações em que cada uma recebeu, em média, menos que $2 \%$ do total repassado para todas as confederações. No segundo bloco, são nove confederações que receberam entre 2, $1 \%$ e $5 \%$ do total. No terceiro bloco, temos oito confederações que receberam mais de $5 \%$ do total (COMITÊ OLÍMPICO BRASILEIRO, 2006; 2007; 2008c).

Para o ano de 2009, o COB divulgou novos critérios para repasse dos recursos para as confederações, visando "diminuir a diferença de valores entre as Confederações e permitir um desenvolvimento mais rápido do esporte brasileiro" (COMITÊ OLÍMPICO BRASILEIRO, 2008b). As confederações foram classificadas em quatro grupos pelo critério de meritocracia, ou seja, de acordo com os resultados em competições: ( I ) modalidades com campeões olímpicos ou conquista de mais de uma medalha em Jogos Olímpicos, (2) modalidades com campeões pan-americanos e/ou histórico olímpico, (3) modalidades em desenvolvimento com resultado sulamericano, pan-americano e mundial e (4) modalidades em desenvolvimento com resultado sul-americano.

Assim, na junção dos valores de 2005 a 2008, incluindo a previsão para o ano de 2009, os percentuais recebidos, por confederação, a cada ano, podem ser vistos na tabela a seguir. 
Tabela I. Estimativa de repasse às confederações brasileiras dos recursos da Lei Agnelo-Piva (percentuais e valores em milhões de reais) - 2005-2009.

(Continua)

\begin{tabular}{|c|c|c|c|c|c|c|c|c|c|c|}
\hline & 2005 & & 2006 & & 2007 & & 2008 & & 2009* & \\
\hline & $\%$ & $\mathrm{R} \$$ & $\%$ & $R \$$ & $\%$ & $R \$$ & $\%$ & $\mathrm{R} \$$ & $\%$ & $\mathrm{R} \$$ \\
\hline $\begin{array}{l}\text { Bloco I: I I } \\
\text { confedera- } \\
\text { ções }\end{array}$ & & 5,6 & $17,4 \%$ & 6,7 & $16,0 \%$ & 5,74 & $16,0 \%$ & 5,44 & $19,9 \%$ & 8 \\
\hline Badminton & $1,6 \%$ & 0,51 & ।,7\% & 0,65 & ।,8\% & 0,66 & $1,6 \%$ & 0,54 & $2,0 \%$ & 0,8 \\
\hline $\begin{array}{l}\text { Beisebol e } \\
\text { Softbol }\end{array}$ & $2,3 \%$ & 0,75 & ।,9\% & 0,75 & $2,1 \%$ & 0,73 & $1,0 \%$ & 0,34 & $0 * *$ & 0 \\
\hline $\begin{array}{l}\text { Desportos } \\
\text { na neve }\end{array}$ & ।,7\% & 0,55 & ।,0\% & 0,37 & $0,9 \%$ & 0,33 & $1,0 \%$ & 0,32 & ।,5\% & 0,6 \\
\hline $\begin{array}{l}\text { Desportos } \\
\text { no gelo }\end{array}$ & ।,7\% & 0,55 & $0,6 \%$ & 0,22 & $0,7 \%$ & 0,24 & $0,8 \%$ & 0,26 & ।,5\% & 0,6 \\
\hline Esgrima & $1,6 \%$ & 0,53 & ।,5\% & 0,57 & ।,8\% & 0,64 & $1,6 \%$ & 0,54 & $2,2 \%$ & 0,9 \\
\hline $\begin{array}{l}\text { Hóquei so- } \\
\text { bre a grama } \\
\text { e indoor }\end{array}$ & $0,6 \%$ & 0,21 & ।,6\% & 0,6 & $1,1 \%$ & 0,38 & $2,3 \%$ & 0,78 & $2,0 \%$ & 0,8 \\
\hline $\begin{array}{l}\text { Levanta- } \\
\text { mento de } \\
\text { peso }\end{array}$ & $1,6 \%$ & 0,52 & ।,7\% & 0,65 & ।,5\% & 0,53 & ।,8\% & 0,62 & $2,0 \%$ & 0,8 \\
\hline $\begin{array}{l}\text { Lutas asso- } \\
\text { ciadas }\end{array}$ & ।,7\% & 0,56 & ।,6\% & 0,61 & ।,5\% & 0,52 & $1,6 \%$ & 0,54 & $2,2 \%$ & 0,9 \\
\hline $\begin{array}{l}\text { Pentatlo } \\
\text { moderno }\end{array}$ & ।,2\% & 0,4 & ।,9\% & 0,76 & $1,5 \%$ & 0,54 & $1,6 \%$ & 0,53 & $2,0 \%$ & 0,8 \\
\hline Taekwondo & ।,5\% & 0,48 & ।,9\% & 0,72 & ।,8\% & 0,64 & $1,3 \%$ & 0,45 & $2,5 \%$ & 1,0 \\
\hline $\begin{array}{l}\text { Tiro com } \\
\text { arco }\end{array}$ & $1,4 \%$ & 0,42 & $2,1 \%$ & 0,8 & $1,4 \%$ & 0,49 & $1,5 \%$ & 0,5 & $2,0 \%$ & 0,8 \\
\hline $\begin{array}{l}\text { Bloco 2: } 9 \\
\text { confedera- } \\
\text { ções }\end{array}$ & & 11,3 & $35,0 \%$ & 13,5 & $31,9 \%$ & 11,45 & $35,1 \%$ & 11,9 & $33,3 \%$ & 13,4 \\
\hline Boxe & $3,6 \%$ & 1,18 & $3,3 \%$ & 1,25 & $2,6 \%$ & 0,94 & $3,3 \%$ & 1,12 & $3,5 \%$ & ।,4 \\
\hline Canoagem & $4,6 \%$ & $|, 5|$ & $3,7 \%$ & 1,43 & $3,7 \%$ & 1,31 & $4,2 \%$ & $|, 4|$ & $4,0 \%$ & 1,6 \\
\hline Ciclismo & $4,1 \%$ & 1,36 & $3,8 \%$ & 1,48 & $3,2 \%$ & 1,15 & $3,0 \%$ & 1,03 & $4,0 \%$ & 1,6 \\
\hline Hipismo & $4,8 \%$ & 1,58 & $5,1 \%$ & 1,98 & $4,5 \%$ & $|, 6|$ & $5,0 \%$ & ।,7 & $4,5 \%$ & 1,8 \\
\hline Remo & $4,7 \%$ & 1,59 & $4,8 \%$ & 1,85 & $4,8 \%$ & $|, 7|$ & $4,6 \%$ & 1,57 & $4,0 \%$ & 1,6 \\
\hline Tênis & $2,7 \%$ & 0,89 & $2,9 \%$ & 1,12 & $3,8 \%$ & 1,37 & $4,2 \%$ & 1,43 & $3,2 \%$ & 1,3 \\
\hline $\begin{array}{l}\text { Tênis de } \\
\text { mesa }\end{array}$ & $4,3 \%$ & 1,4 & $4,2 \%$ & 1,63 & $3,5 \%$ & 1,26 & $4,0 \%$ & 1,38 & $4,0 \%$ & 1,6 \\
\hline $\begin{array}{l}\text { Tiro espor- } \\
\text { tivo }\end{array}$ & $2,7 \%$ & 0,9 & $4,0 \%$ & ।,55 & $3,3 \%$ & 1,17 & $3,5 \%$ & 1,18 & $3,2 \%$ & 1,3 \\
\hline
\end{tabular}




\begin{tabular}{|c|c|c|c|c|c|c|c|c|c|c|}
\hline & 2005 & & 2006 & & 2007 & & 2008 & & $2009 *$ & \\
\hline & $\%$ & $R \$$ & $\%$ & $R \$$ & $\%$ & $\mathrm{R} \$$ & $\%$ & $\mathrm{R} \$$ & $\%$ & $R \$$ \\
\hline Triathlon & $2,8 \%$ & 0,91 & $3,1 \%$ & 1,19 & $2,5 \%$ & 0,89 & $3,2 \%$ & I,08 & $3,0 \%$ & 1,2 \\
\hline $\begin{array}{l}\text { Bloco 3: } 8 \\
\text { confedera- } \\
\text { ções }\end{array}$ & & 16,0 & $47,6 \%$ & 18,4 & $52,1 \%$ & 18,7 & $48,9 \%$ & 16,6 & $46,8 \%$ & 18,8 \\
\hline Atletismo & $5,5 \%$ & $|, 8|$ & $6,1 \%$ & 2,37 & $5,0 \%$ & ।,79 & $5,8 \%$ & 1,98 & $6,2 \%$ & 2,5 \\
\hline Basketball & $4,8 \%$ & 1,56 & $6,4 \%$ & 2,49 & $5,1 \%$ & 1,84 & $6,5 \%$ & 2,22 & $4,2 \%$ & 1,7 \\
\hline $\begin{array}{l}\text { Desportos } \\
\text { Aquáticos }\end{array}$ & $6,8 \%$ & 2,22 & $7,2 \%$ & 2,77 & $5,2 \%$ & 1,86 & $7,0 \%$ & 2,36 & $6,2 \%$ & 2,5 \\
\hline Ginástica & $6,3 \%$ & 2,07 & $5,5 \%$ & 2,1 & $5,6 \%$ & 2,02 & $5,6 \%$ & $|, 9|$ & $5,7 \%$ & 2,3 \\
\hline Handebol & $5,6 \%$ & 1,83 & $3,8 \%$ & 1,48 & $7,9 \%$ & 2,83 & $5,8 \%$ & 1,99 & $5,7 \%$ & 2,3 \\
\hline Judô & $5,5 \%$ & 1,79 & $5,8 \%$ & 2,24 & $4,3 \%$ & 1,53 & $4,2 \%$ & 1,43 & $6,2 \%$ & 2,5 \\
\hline $\begin{array}{l}\text { Vela e } \\
\text { motor }\end{array}$ & $5,9 \%$ & 1,93 & $7,0 \%$ & $2,7 \mid$ & $9,6 \%$ & 3,44 & $6,7 \%$ & 2,28 & $6,2 \%$ & 2,5 \\
\hline Voleibol & $8,5 \%$ & 2,8 & $5,8 \%$ & 2,25 & $9,3 \%$ & 3,35 & $7,1 \%$ & 2,42 & $6,2 \%$ & 2,5 \\
\hline Total & $100 \%$ & 32,9 & $100 \%$ & 38,7 & $100 \%$ & 35,9 & $100 \%$ & 34,0 & $100 \%$ & 40,2 \\
\hline
\end{tabular}

Fonte: A autora (2010)

Nota: * Previsão; **Beisebol e softbol são modalidades que deixaram de fazer parte do programa olímpico, por isso não recebem recursos do COB a partir desde 2009.

Não poderíamos deixar de notar a diferença nos repasses entre as confederações brasileiras. Enquanto onze dividem em média pouco mais que 16\% das verbas repassadas, outras oito recebem praticamente $50 \%$, como observamos no período. Outro fator que deve ser considerado é que, das oito confederações brasileiras que recebem mais recursos, somente a Confederação Brasileira de Vela e motor não teve patrocínio durante todo o período observado.

Apesar da declaração de mudança no critério dos repasses para o ano de 2009, somente a Confederação Brasileira de Hipismo e a Confederação Brasileira de Taekwondo tiveram uma mudança de posicionamento, recebendo um percentual maior que dos anos anteriores, e a Confederação Brasileira de Basketball teve uma queda no percentual de verbas recebidas.

Quanto à estrutura das confederações brasileiras, os relatórios de demonstração de recursos da Lei Agnelo-Piva nos trazem subsídios interessantes para traçar um esboço da estrutura física e administrativa das modalidades olímpicas no país. 
Observando as confederações brasileiras que possuem mais recursos, veremos que, salvo poucas exceções e particularidades da prática entre as modalidades, elas possuíram, durante praticamente todo o período observado, patrocínio, fornecedores de materiais, infraestrutura para a preparação dos atletas e equipes e representatividade de federações em praticamente todos os estados brasileiros. Já as confederações brasileiras com menores recursos apresentam um quadro inverso.

Quando observamos a existência de patrocinadores das confederações brasileiras, notamos um quadro bastante heterogêneo entre elas, nas quais destacamos quatro situações diferentes: o caso do futebol, do voleibol, de confederações brasileiras com patrocínio de empresas com capital público e confederações brasileiras sem patrocínio.

O futebol é gerido pela CBF, que possui diversos patrocinadores, assim como as principais equipes de alto nível do futebol brasileiro. Sendo a única Confederação Brasileira que não é patrocinada por empresas estatais, possui três patrocinadores oficiais (CBF anuncia contrato..., 2008): uma empresa nacional (Itaú) que numa recente fusão se tornou market leader ${ }^{3}$ no hemisfério sul; uma empresa multinacional (Vivo) que é market leader nacional e internacional; e outra empresa também multinacional (Nike), fornecedora de artigos esportivos, que é market leader nacional e internacional.

Já o voleibol, embora sua confederação (CBV) possua o patrocínio de uma empresa com capital público ${ }^{4}$, o Banco do Brasil, as equipes da liga nacional têm, em sua maioria, patrocínios de empresas privadas associadas às prefeituras dos municípios onde treinam.

Excetuando os casos da CBF (com patrocínio privado) e da CBV (com patrocínio de empresa com capital público e equipes com patrocínios privados) já citados, as demais confederações se dividem em dois grupos.

No primeiro grupo estão aquelas confederações que possuem patrocínio de empresas com capital público e poucos atletas ou equipes conseguem patrocínios privados. Das treze confederações brasileiras com patrocínio em 2008, segundo

3. Market leaders ou first movers são considerados os dominantes de determinado nicho de mercado, ou subcampo do campo econômico. Eles costumam agir com alteração de preços, lançamento de produtos, promoção, distribuiçãa ou até utilizando-se do blefe, como forma de defesa e para que os dominados se posicionem tendo-os como parâmetro. Dessa maneira, intimidam os concorrentes e redobram o poder de seu capital simbólico. Aos dominados, os challengers, restam alternativas de especializar-se em lacunas de nichos de mercado deixadas pelos market leaders (BOURDIEU, 2005).

4. Utilizamos o termo empresas com capital público (ou estatal) como referência tanto às empresas estatais (controladas pelo Estado) como as sociedades de economia mista (que tem a concorrência de capital público e privado). Essa diferenciação está presente no Decreto-Lei no 900 de 29 de setembro de 1969 (BRASIL, 2004). 
relatório do COB (COMITÊ OLÍMPICO BRASILEIRO, 2008c), uma é o futebol e outras oito, além do voleibol, possuem empresas com capital público como patrocinadoras. São elas: atletismo, ginástica e lutas associadas (Caixa Econômica Federal); basquete (Eletrobrás); handebol (Petrobras); judô (Infraero); desportos aquáticos e tênis (Correios). De acordo com esse mesmo relatório, outras três (canoagem, desportos na neve e tênis de mesa) teriam patrocínio em 2008, mas não pudemos encontrar informações de quais seriam essas empresas.

Para compreender a situação no campo econômico das empresas com capital público é preciso diferenciar os casos de monopólio de serviços estatais (como Correios, Eletrobrás e Infraero) e das empresas que estão em concorrência de mercado (como Banco do Brasil e Caixa Econômica Federal). Assim, observa-se que a maioria busca sua manutenção como market leader em território brasileiro, sendo que uma (Petrobras) possui capital atual e potencial mais evidente para estender sua posição dominante no contexto internacional.

No segundo grupo, estão 16 confederações que não possuem nenhum patrocinador oficial: badminton, beisebol, boxe, ciclismo, desportos no gelo, esgrima, hipismo, hóquei sobre a grama, levantamento de peso, pentatlo moderno, remo, beisebol e softbol, taekwondo, tiro esportivo, triathlon e vela. Dessas, apenas pentatlo moderno, tiro esportivo e triathlon tiveram patrocínio durante o ciclo olímpico de 2005 a 2008.

Aqui pudemos observar as diferentes estratégias que empresas do campo econômico utilizam com o patrocínio ao esporte no Brasil. Na modalidade mais visível internacionalmente e que possui como capital simbólico a característica de melhor do mundo, várias empresas multinacionais, que também são bem estabelecidas no mercado internacional, têm interesse no patrocínio. Modalidades com menor expressão internacional, porém com importância dentro do contexto brasileiro, têm o apoio de empresas com capital público.

\section{DISCUSSÃO}

Sobre os recursos provenientes da Lei Agnelo-Piva, é possível perceber uma centralização das decisões no COB, que é a entidade responsável por aceitar ou refutar os projetos das confederações que receberão os recursos através dessa lei. Esse fato nos leva a refletir se a tendência na manutenção de dirigentes, por exemplo, tanto no $\mathrm{COB}$ quanto nas confederações não é reforçada pela estrutura atual. Trazemos essa discussão em virtude das recentes críticas da mídia à manutenção de presidentes de confederações (DORO, 2008) e do próprio COB no poder.

A assembleia que reelegeu o presidente Carlos Arthur Nuzman em 02 de outubro de 2008 sofreu críticas porque teria sido realizada "às escuras", pois seu 
anúncio ocorreu em jornais de pouca circulação e o aviso aos dirigentes de confederações teria sido com poucos dias de antecedência, o que dificultaria a mobilização de chapas opositoras. No dia seguinte a eleição, o COB divulgou uma nota de esclarecimento em seu endereço eletrônico na internet, afirmando que a eleição foi realizada conforme as regras estatutárias da entidade (COMITÊ OLÍMPICO BRASILEIRO, 2008d).

Rubio (2005) considera que a adoção do modelo de administração do COI, tradicional e criado pelo seu fundador, Barão de Coubertin, cooperam para a situação evidenciada no caso brasileiro:

O fortalecimento de uma elite dominante, o desenvolvimento de mecanismos de controle político das instituições, a permanência por longos períodos de tempo à frente das organizações esportivas e o afastamento dos atletas dos âmbitos de poder também se deram no Brasil como na grande maioria dos Comitês Olímpicos Nacionais espalhados pelo mundo, reforçando um modelo institucional fechado, burocratizado e autoritário. (RUBIO, 2005, s. p.)

Esse modelo fechado, burocratizado, autoritário, e poderíamos incluir centralizador, está evidenciado na distribuição de verbas para as confederações brasileiras. $\bigcirc$ processo para liberação dessas verbas se dá pela elaboração de planos de trabalho e orçamentário anual pelas confederações, sendo que os projetos devem ser enviados e aprovados para que haja o repasse pelo COB. Sua execução fica a cargo das confederações, assim como a prestação de contas, que será acompanhada pelo COB.

Nesse ponto, podemos supor que as oito confederações brasileiras que recebem mais verbas podem ter um melhor gerenciamento nesse processo burocrático, o que permite maior aprovação de projetos e consequente recepção de recursos. Ao mesmo tempo, questionamos se tal fato não indicaria a necessidade de maior atenção e capacitação dos gestores das outras confederações, para que possam elaborar e executar projetos conforme as exigências do COB. A partir do momento em que há um melhor gerenciamento, as verbas recebidas podem ser aplicadas de forma efetiva no desenvolvimento das modalidades, trazendo resultados esportivos, o que futuramente pode gerar o interesse de patrocinadores privados. A manutenção dessa forma de administração dos recursos, a nosso ver, somente mantém a distância entre as confederações, cuja administração e recebimento ou não dos recursos interfere diretamente nos resultados nas competições.

Com o discurso de repasse por meritocracia para 2009, anteriormente questionamos se essa seria a melhor perspectiva de distribuição dos recursos. A situação nos repasses se mantém de maneira idêntica aos anos anteriores, com poucas confederações recebendo bem mais recursos que outras. Parece-nos paradoxal entender 
que a meritocracia acelerará o desenvolvimento do esporte no país e diminuirá as diferenças entre as confederações, já que as modalidades com campeões olímpicos ou históricos de resultados em Jogos Olímpicos, que são capazes de atrair recursos da iniciativa privada, continuarão recebendo mais recursos, em oposição às modalidades de resultados locais.

Esse modelo prioriza a classificação que é utilizada quando as conquistas e o sucesso da nação são quantificados pelo posicionamento no ranking de medalhas. As modalidades incluídas nos Jogos Olímpicos são aquelas que possuem maior visibilidade midiática mundial e grande interesse do público. Os dirigentes esportivos e políticos ligados ao esporte costumam estar presentes nesses momentos de conquista, trazendo para si a boa imagem de "responsável pelo sucesso". Na verdade, a conquista de uma medalha em campeonatos mundiais ou em uma edição dos Jogos Olímpicos pode não representar um projeto político-esportivo bem sucedido.

Porém, o simbolismo da medalha e o nacionalismo que essa imagem representa são suscetíveis de conversão em capital político, numa proporção de alcance nacional e internacional proporcionado principalmente pela televisão (BOURDIEU, 1997), diferentemente do investimento em outras manifestações de esporte (escolar, lazer e saúde/qualidade de vida), que teriam um alcance local ou regional.

Numa relação de mútua influência com este quadro apresentado, percebemos no decorrer desse mapeamento algumas relações entre o que chamamos de confederações brasileiras dominadas e dominantes que podem ser observadas no esporte olímpico brasileiro quanto ao capital econômico para o período observado, ou seja, pelo recebimento de recursos tanto do COB como das empresas patrocinadoras com capital público.

As razões para estarem nessas posições de dominados ou dominantes são variáveis para cada caso e estão relacionadas ao seu processo histórico de construção social. Na análise que realizamos deste quadro atual, apesar da observação a partir do capital econômico, percebemos algumas características que parecem ser decisivas e podem influenciar ou modificar o posicionamento que descrevemos, como a visibilidade da modalidade e o reconhecimento público que ela possui (capital simbólico), sua organização administrativa juntamente com uma aproximação de outros dirigentes esportivos e até políticos (capital social) além dos resultados em competições internacionais importantes (que podemos entender como um "capital cultural do esporte").

A passagem do amadorismo para o profissionalismo no Movimento Olímpico, que é evidenciado hoje dentro do esporte profissional e de rendimento, só foi possível a partir de forte investimento financeiro e o vislumbre de retorno proporcional. É neste ponto que vemos o desenvolvimento dos meios de comunicação 
como essencial para viabilizar retorno financeiro aos investidores e possibilitar assim a profissionalização esportiva (BOURDIEU, 1983; 2004).

A distinção social, buscada pelas elites na gênese do esporte moderno, continua presente no campo das práticas esportivas e caracteriza, em parte, as formas pelas quais se darão as lutas: pela tentativa do "monopólio de imposição da definição legítima da prática esportiva e da função legítima da atividade esportiva" (BOURDIEU, 1983, p. 142).

O COl é uma entidade que atualmente se destaca como detentor desse monopólio porque, ao ter o poder de gerenciar as modalidades presentes nos Jogos Olímpicos de verão e inverno, inclui ou exclui determinadas práticas do cenário esportivo mundial 5 . Essa posição de destaque, que é transferida para o COB no contexto nacional, legitima as ações dos agentes a frente dessa instituição no campo esportivo.

A posição das confederações brasileiras dominadas, dada a tendência mercantil e de alto desempenho do esporte olímpico, tendem a manter-se até que relevantes mudanças na lógica do campo aconteçam. Por exemplo, a "necessidade" de aumentar a quantidade de medalhas conquistadas nos Jogos Olímpicos que serão realizados no país (com grande influência das lógicas também do campo político) pode gerar investimento financeiro em outras modalidades que estão em menor evidência, mas que têm potencial para proporcionar bons resultados ${ }^{6}$.

\section{CONSIDERAÇÕES FINAIS}

Orecebimento de recursos através da Lei Agnelo-Piva tem sido a fonte mais significativa quantitativamente para o $\mathrm{COB}$ e também para apoio às confederações brasileiras das modalidades olímpicas. Para muitas delas, essa é a única fonte de recursos e reforçam sua dependência ao COB.

Intentamos mostrar que as políticas de repasse do $C O B$ às confederações brasileiras são questionáveis, porque as exigências favorecem modalidades que possuem estruturas administrativas aptas para solicitação de verbas através de projetos e, segundo os novos critérios adotados para 2009, que possuam resultados em competições esportivas internacionais.

A disparidade dos recursos recebidos entre as confederações brasileiras ficou evidente quando elencamos numa tabela os percentuais recebidos a cada ano, o

5. A inclusão de modalidades nos Jogos Olímpicos de Verão e Inverno se dá pela proposta do comitê executivo do COI. As propostas devem respeitar diversos critérios estabelecidos na carta olímpica, para que sejam escolhidas as modalidades através de votação em sessões que incluem também as Federações Internacionais (INTERNATIONAL OLYMPIC COMMITTEE, 2007).

6. Cf. Mattos (20।0). 
que nos mostrou que as confederações brasileiras com patrocínio recebem muito mais verbas que aquelas que não o possuem. Por essa situação, refletimos sobre a existência de confederações e ou modalidades dominadas e dominantes no campo do esporte olímpico brasileiro, sob o ponto de vista do capital econômico, mas que é influenciado pelo capital simbólico, quando se leva em consideração os resultados em competições internacionais.

Entendemos que esse capital simbólico é adquirido em um médio prazo, quando percebemos que uma estrutura econômica e administrativa, somada à popularidade e um número significativo de praticantes da modalidade no país, proporciona condições para a conquista de campeonatos mundiais ou medalhas em Jogos Olímpicos, assim como patrocinadores. Identificamos que esses aspectos são as condições relevantes no quadro atual, mas a compreensão de como uma confederação adquiriu ou deixou de adquirir esse capital simbólico exige um olhar mais aprofundado de cada caso, que perpassa a compreensão da construção histórica e social de cada subcampo.

Consideramos também, nesses sucessos, a existência de atletas que se destacam por esforços próprios e/ou com a ajuda de patrocinadores individuais, que mesmo sem o apoio das confederações brasileiras de suas modalidades, conquistam excelentes resultados. Independente da influência ou não da confederação brasileira, esses fatos proporcionam mais visibilidade, aumento nos recursos e a possibilidade de manutenção ou inserção na posição dominante sob o ponto de vista do capital econômico.

Em se tratando de patrocínio, vimos que as relações mais duradouras, ou que pelo menos duraram os quatro anos do ciclo olímpico analisado, foram de empresas com capital público. Atletismo, basquete, desportos aquáticos, ginástica, handebol, judô, lutas associadas, tênis e voleibol tiveram o patrocínio das empresas Caixa Econômica Federal, Eletrobrás, Correios, Banco do Brasil, Petrobras e Infraero. Esses patrocínios, que carecem de pesquisa mais aprofundada, podem representar não só o interesse público governamental no esporte, mas quadros específicos de razões para esse tipo de investimento, já que muitas dessas empresas não estão inseridas na lógica competitiva em seus ramos de atuação, mas somente como monopólios estatais.

Dada a atual conjuntura esportiva do Brasil, quando nos próximos anos teremos importantes mega-eventos esportivos, é primordial o questionamento da realidade das modalidades olímpicas brasileiras. Buscamos trazer algumas colaborações através de uma leitura crítica da realidade observada nos últimos anos quanto às opções gerenciais e de financiamento das confederações brasileiras. A nosso ver, a divisão de verbas e prioridades na gestão dos recursos precisam ser, 
no mínimo, revistas se a intenção é o desenvolvimento dessas modalidades para os próximos anos.

Brazilian Olympic Committee and the funding of Brazilian confederations ABSTRACT: The Olympic Sport in Brazil has as main management institutions the Brazilian Olympic Committee (COB) and the Brazilian Confederations of Olympic sports. But how they interact financially and how does this relation influence the dynamic of Brazilian sporting field? After data collection in official reports and with theoretical subsidies of Pierre Bourdieu, we could find that the $C O B$ transferences to Brazilian Confederations reinforce dominant and dominated positions in the sporting field. COB justifies this current management in a paradox mean if we compare that this entity proposes the development of sport. In this sense, we consider that some Bourdieu's concepts can unveil hidden mechanisms of domination in the sporting field of the 2016 Olympic Games host country.

KEY WORDS: Brazil; Sport; organization and administration; financing.

\section{Comité Olímpico Brasileño y la financiación de las confederaciones brasileñas}

RESUMEN: El deporte olímpico en Brasil tiene como importantes instituciones de administración el Comité Olímpico Brasileño (COB) y las Confederaciones Brasileñas de modalidades olímpicas. ¿Pero de manera ellas se relacionan financieramente y como eso interfiere en la dinámica del campo deportivo brasileño? Con la coleta de datos en informes oficiales y con el subsidio teórico del sociólogo Pierre Bourdieu, percibimos que los repases del COB a las Confederaciones Brasileñas refuerzan las posiciones dominantes y dominadas en el campo deportivo. La justificativa para las actuales políticas de repases son paradoxales a la propuesta de desarrollo del deporte en Brasil. En ese sentido, algunos conceptos de Bourdieu ayúdanos en desvelar algunos fundamentos ocultos de dominación en el campo deportivo del país sede de los Juegos Olímpicos de 2016.

PALABRAS CLAVE: Brasil; deporte; organización y administración; financiación.

\section{REFERÊNCIAS}

ABREU, Neíse. et al. Comitê Olímpico Brasileiro - COB. In: DACOSTA, Lamartine (org.). Atlas do Esporte no Brasil. Rio de Janeiro: CONFEF, 2006, p. 3.I4-3. 15.

ALMEIDA, Bárbara Schausteck. O financiamento do esporte olímpico e suas relações com a política no Brasil. 20 I0. I 19 f. Dissertação (Mestrado em Educação Física) - Departamento de Educação Física, Universidade Federal do Paraná, Curitiba.

BOURDIEU, Pierre. Como se pode ser esportivo? In: Questões de Sociologia. Rio de Janeiro: Marco Zero, 1983. 
BRASIL. Decreto Lei n 10.264, de 16 de julho de 2001 . Acrescenta inciso e parágrafos ao artigo 56 da lei 9.615 , de 24 de março de 1998, que institui normas gerais sobre desporto. Diário Oficial [da] República Federativa do Brasil, Brasília, v. I 38, n. 137, p. I , 17 jul. 200 I. Seção I, pt. I.

Decreto-lei no 900 de 29 de setembro de 1969. Altera disposições do Decreto-lei n²00, de 27 de fevereiro de 1967, e dá outras providências. Diário Oficial [da] República Federativa do Brasil, Brasília, v. 107, n. 187, s.p., 30 set. 1969. Seção I, pt. I.

Os Jogos Olímpicos. In: Sobre a televisão. Rio de Janeiro: Jorge Zahar Editor, 1997.

Programa para uma sociologia do esporte. In: Coisas Ditas. São Paulo: Brasiliense, 2004.

( campo econômico. Revista Política \& Sociedade, Florianópolis, v. 4, n. 6, p. 15-57, abril 2005.

CBF anuncia contrato de patrocínio com Itaú de cerca de R\$200 milhões. Folha Online, São Paulo, 20 out. 2008. Disponível em: <http://wwwl.folha.uol.com.br/folha/esporte/ ult92u45903 I.shtml>. Acesso em: I2 nov. 2008.

COMITÊ OLÍMPICO BRASILEIRO. 90 anos do Comitê Olímpico Brasileiro. Rio de Janeiro: COB, 2004a.

Estatuto 2004. Rio de Janeiro: COB, 2004b.

- Demonstração da aplicação dos recursos provenientes da Lei Agnelo Piva 2006. Disponível em: <http://www.cob.org.br/site/downloads/downloads/2007/lei_agnelo_2006. zip>. Acesso em: 26 mai. 2008.

Demonstração da aplicação dos recursos provenientes da Lei Agnelo Piva 2007. Disponível em: <http://www.cob.org.br/downloads/downloads/2007/lei_agnelo_2007.zip>. Acesso em: 15 dez. 2008.

Estatuto 2007. Rio de Janeiro: COB, 2008a.

$C O B$ redistribui verbas e diminui diferença de valores entre as confederações. Rio de Janeiro, 03 dez. 2008b. Disponível em: < http://www.cob.org.br/noticias/noticias_interna.asp?id=|4384>. Acesso em: 24 fev. 2009.

Demonstração da aplicação dos recursos provenientes da Lei Agnelo Piva 2008c. Disponível em: <http://www.cob.org.br/downloads/downloads/2008/Demonstracao_Lei_Agnelo-Piva_2008.zip >. Acesso em: 28 ago. 2008.

Esclarecimento - Sobre a assembleia do COB. Rio de Janeiro, 03 out. 2008d. Disponível em: <http://www.cob.org.br/noticias/noticias_interna.asp? id = | 4255>. Acesso em: 07 out. 2009. 
DORO, Bruno. "Era Nuzman" ajuda a perpetuar cartolas eternos no esporte olímpico. Folha de São Paulo, São Paulo, 10 out. 2008. Disponível em: < http://esporte.uol.com.br/ ultimas/2008/I 0/I 0/ult58u I 209.jhtm> . Acesso em: 07 out. 2009.

INTERNATIONAL OLYMPIC COMMITTEE. Olympic Charter - In force as from 7 July 2007. Disponível em: < http://multimedia.olympic.org/pdf/en_report_122.pdf>. Acesso em: 18 fev. 2009.

MATTOS, Rodrigo. Já com meta, COB define estratégia para os Jogos do Rio-20 I6. Folha de São Paulo, São Paulo, 17 out. 20 I0. Disponível em: <http://wwwl.folha.uol.com.br/ esporte/8 I 5749-ja-com-meta-cob-define-estrategia-para-os-jogos-do-rio-20 I 6.shtml> . Acesso em: 19 nov. 2010.

PLATAFORMA OLÍMPICA UGF. Centro de Estudos Olímpicos UGF. Disponível em: $<$ http://www.ugf.br/editora/ceo/index.html >. Acesso em: 18 nov. 2010.

RICHARDSON, Roberto Jarry. Pesquisa social: métodos e técnicas. São Paulo: Atlas, 2008. RUBIO, Kátia. Da Europa para a América: a trajetória do Movimento Olímpico brasileiro. Geo Crítica/Scripta Nova. Revista electrónica de geografía y ciencias sociales, Barcelona, v. 9, n. 200, s.p., nov. 2005.

Recebido: 16 abr. 2010 Aprovado: 22 nov. 2010

Endereço para correspondência: Bárbara Schausteck de Almeida Rua Nicarágua, 400/08 - Bairro Bacacheri Curitiba - PR CEP: $82.510-170$ 